Article

\title{
Sulfonated Poly(ether ether ketone) Doped with Ammonium Ionic Liquids and Nano-Silicon Dioxide for Polymer Electrolyte Membranes
}

\author{
Shuguo $\mathrm{Qu}{ }^{1, *}$, Minhui $\mathrm{Li}^{1}{ }^{1}$, Chenchen Zhang ${ }^{1}$, Yuanyuan Sun ${ }^{1}$, Jihai Duan ${ }^{1}$, Weiwen Wang ${ }^{1}$, \\ Jianlong $\mathrm{Li}^{1}$ and Xiaojin $\mathrm{Li}^{2, *}$ \\ 1 Key Laboratory Reactions and Isolations of Muti-phases Liquid of Shandong Province, College of Chemical \\ Engineering, Qingdao University of Science \& Technology, Qingdao 266042, Shandong, China; \\ lime0103@163.com (M.L.); 17864213202@163.com (C.Z.); m15969627512@163.com (Y.S.); \\ duanjihai@qust.edu.cn (J.D.); wangweiwenqd@163.com (W.W.); ljlong321@163.com (J.L.) \\ 2 Energy Storage Management and Equipment Group, Qingdao Institute of Bioenergy and Bioprocess \\ Technology, Chinese Academy of Sciences, Qingdao 266101, Shandong, China \\ * Correspondence: shuguoqu@163.com (S.Q.); lixj@qibebt.ac.cn (X.L.); \\ Tel.: +86-187-6620-3088 (S.Q.); +86-153-1877-8258 (X.L.)
}

Received: 15 October 2018; Accepted: 17 December 2018; Published: 21 December 2018

\begin{abstract}
Nano-silicon dioxide $\left(\mathrm{SiO}_{2}\right)$ was incorporated into the matrix of sulfonated poly(ether ether ketone) (SPEEK)/ammonium ionic liquid (AIL) membranes by solution casting, with the aim of reducing ionic liquid leaching and any consequent decrease in proton conductivity. Fourier transform infrared (FTIR) spectra results indicate incorporation of the SPEEK matrix with AIL and nano-SiO ${ }_{2}$. Scanning electron microscopy (SEM) and X-ray diffraction (XRD) images revealed that incorporation of nano- $\mathrm{SiO}_{2}$ make the ternary composite membranes more flexible. The maximum ion exchange capacity (IEC) value was $3.25 \mathrm{meq} / \mathrm{g}$, and the net structure formed by the nano- $\mathrm{SiO}_{2}$ not only retarded AIL leaching, but also increased the proton conductivity of the composite membranes. AIL leaching from the membranes was between $20 \%$ and $30 \%$, which was lower than that of the SPEEK/AIL membrane. The maximum proton conductivity for the SPEEK/AIL/SiO $\mathrm{membranes}$ reached $10.73 \mathrm{mS} / \mathrm{cm}$ at $393 \mathrm{~K}$.
\end{abstract}

Keywords: sulfonated poly(ether ether ketone); ammonium ionic liquids; nano silicon dioxide; leaching; proton conductivity

\section{Introduction}

Fuel cells offer high power densities and energy conversion efficiencies, and also produce limited amounts of environmental pollution; they are thus considered to be clean energy sources that have the potential to replace fossil fuels [1]. Of the different fuel cell types, the polymer electrolyte membrane fuel cell (PEMFC) has attracted substantial attention because of its particular advantages, such as its rapid start-up at room temperature [2]. The polymer electrolyte membrane (PEM) is one of the critical components of the PEMFC, and it is used in proton conduction and to prevent fuel mixing. However, to date, only membranes based on perfluorosulfomic acid (PFSA), such as Nafion (Dupont) and GORE-SELECT (W.L. Gore and Associates. Inc.), have been considered competent enough for use in practical PEMFC applications, because of their good chemical and mechanical stability and high proton conductivity [3-5]. The PFSA membrane depends on water to transmit protons in the form of $\mathrm{H}_{3} \mathrm{O}^{+}$, but it has a high cost of $\$ 500-800$ per $\mathrm{m}^{-2}$ and provides extremely low proton conductivity $\left(0.5 \mathrm{mS} \mathrm{cm}^{-1}\right)$ at high temperatures $(>373 \mathrm{~K})$ in relation to the evaporation of water. In contrast, the high-temperature PEMFC (HT-PEMFC) operates under low humidity and even 
anhydrous conditions. It also has many other merits: it tolerates impure fuel streams (with a CO tolerance of $1000 \mathrm{ppm}$ at $403 \mathrm{~K}$ ), employs an uncomplicated method to manage water and heat, and has quicker electrode reaction kinetics [6,7]. Therefore, a considerable amount of research has been conducted with the aim of developing a new type of low-cost PEM with high proton conductivity, for use in HT-PEMFCs.

Many types of electrolytes have been prepared for HT-PEMFCs over the past decades [8-12]: modified PFSA membranes, blend polymer electrolyte membranes, polybenzimidazole $(\mathrm{PBI}) / \mathrm{H}_{3} \mathrm{PO}_{4}$ membranes, and ionic liquids/polymer membranes. Of these, the sulfonated poly(ether ether ketone) (SPEEK) membrane has been identified as a reasonable replacement for the PFSA as a PEM, because of its unique tensile strength, low development cost, high chemical resistance, and thermal stability $[13,14]$. To further improve the proton conductivity of SPEEK, some researchers have incorporated inorganic oxides into the original membrane [15-18], including silicon dioxide $\left(\mathrm{SiO}_{2}\right), \mathrm{TiO}_{2}, \mathrm{ZrO}_{2}$, which have high melting points, good chemical stabilities, perfect moisture absorption properties, and provide excellent mechanical performances. Prior to use, these inorganic oxides are treated by modifying their surfaces or making them nano-sized to improve their specific surface area, which thus strengthens their ability to adsorb and desorb water molecules. For example, Mossayebi [15] found that SPEEK incorporated with sulfated zirconia nanoparticles had higher proton conductivity, oxidative stability, and water absorption capability, and the maximum proton conductivity of a SPEEK/sulfonated zirconia was found to reach $3.88 \mathrm{mS} / \mathrm{cm}$ at $100 \%$ relative humidity (RH) and $373 \mathrm{~K}$. However, Li [16] prepared a cross-linking hybrid membrane incorporating $3 \%-8 \% \mathrm{SiO}_{2}$, and observed a decrease in the proton conductivity, although the dimensional stability of the membrane improved when the mass fraction of $\mathrm{SiO}_{2}$ within it increased. Salarizadeh [17] incorporated amine-functionalized iron titanate (AIT) into a SPEEK polymer matrix, and the proton conductivity of the obtained SPEEK/AIT membrane was observed to reach $120 \mathrm{mS} / \mathrm{cm}$ at $353 \mathrm{~K}$, in relation to the water channels formed at the interface between the polymer and nanoparticle; the connectivity of water channels provided an increase in the number of direct proton conduction routes. As ionic liquids (IL) possess certain merits, such as high proton conductivity, low viscosity, negligible vapor pressure, and good electrochemical and thermal stability [19], other researchers [20,21] have attempted to incorporate IL within the SPEEK matrix to enhance membrane proton conductivity. In this respect, the proton conductivity of a SPEEK/alkylimidazolium membrane reaches $3.16 \mathrm{mS} / \mathrm{cm}$ under anhydrous conditions at $418 \mathrm{~K}$, and the highest power density of the PEMFC using the prepared membrane reaches $203 \mathrm{~mW} / \mathrm{cm}^{2}$ at $418 \mathrm{~K}$ [21]. However, SPEEK/IL membranes undergo IL leaching when the PEMFC is running for a long time, which ultimately causes attenuation of membrane proton conductivity and fuel cell performance [20]. In our previous study [22], ammonium ionic liquid (AIL) was fabricated and incorporated within the SPEEK matrix to enhance compatibility between the ionic liquid and the $\mathrm{Pt} / \mathrm{C}$ catalyst. However, neither proton conductivity nor the AIL loss rate of SPEEK/AIL membranes reached our expectations. Therefore, in this study, AIL and nano-SiO ${ }_{2}$ were incorporated into the matrix of SPEEK, with the aim of enhancing proton conductivity and AIL retention within the SPEEK/AIL membrane.

In this study, SPEEK/AIL/ $\mathrm{SiO}_{2}$ ternary composite membranes were fabricated using a solution casting method. Ternary composite membrane morphology was characterized by Fourier transform infrared (FTIR), scanning electron microscopy (SEM), and X-ray diffraction (XRD). In addition, thermogravimetric analysis (TGA) was used to evaluate thermal stability. The electrochemical characteristics of the SPEEK/AIL/ $\mathrm{SiO}_{2}$ composite membranes, such as IEC, proton conductivity, and AIL leaching, were also analyzed.

\section{Experimental}

\subsection{Sulfonated Poly(ether ether ketone)/Ammonium Ionic Liquid/Silicon Dioxide Composite Membrane Preparation}

SPEEK was manufactured using the direct sulfonation method. First, $5 \mathrm{~g}$ of poly(ether ketone) (PEEK; 450 PF, purchased from Victrex Inc., Houston, TX, USA) was dissolved in $95 \mathrm{~mL}$ sulfuric acid 
(98 wt \%) and agitated vigorously for 3-12 h at 313-353 K [23]. The mixed solution was then added slowly to iced water under stirring. The precipitate was washed repeatedly with de-ionized water until a pH of 7 was attained, and it was then dried in a vacuum oven at $353 \mathrm{~K}$ for $20 \mathrm{~h}$. The degree of sulfonation (DS) of the prepared SPEEK was detected using the ${ }^{1} \mathrm{H}$ nuclear magnetic resonance (NMR) spectrum [24].

Neutralization was used to make the AIL [25]. $\mathrm{H}_{2} \mathrm{SO}_{4}$ was mixed with triethylamine at $333 \mathrm{~K}$ for $1 \mathrm{~h}$ under continual stirring, and the mixed solution was then heated to $343 \mathrm{~K}$ for $3 \mathrm{~h}$. The reaction product was purified at $353 \mathrm{~K}$ in a rotary evaporator, until the quality of the remaining amount was unchanged. Ultimately, the prepared AIL was ammonium hydrogen sulfate $\left(\left[\left(\mathrm{CH}_{3} \mathrm{CH}_{2}\right)_{3} \mathrm{NH}^{+}\right]\right.$ $\left[\mathrm{HSO}_{4}^{-}\right]$, TEAS) [22].

Nano- $\mathrm{SiO}_{2}$ was prepared using a sol-gel method. Tetraethyl orthosilicate (TEOS) was added to ethanol, and hydrochloric acid $(\mathrm{HCl})$ was then added dropwise. The molar ratio of HCl:ethanol:TEOS: $\mathrm{H}_{2} \mathrm{O}$ was 10:6:1:30. The solution was mixed by magnetic stirring for $3 \mathrm{~h}$ at $333 \mathrm{~K}$ to form a colorless and transparent solution, and then dried in a vacuum oven at $333 \mathrm{~K}$ for $24 \mathrm{~h}$ to produce a colorless gel. When the gel had dried, it was crushed into a fine powder using a mortar, and then stored in a zip lock bag for future use.

The SPEEK/AIL/ $\mathrm{SiO}_{2}$ composite membranes were fabricated using a solution casting method. First, the nano-SiO 2 powder and AIL were added into SPEEK/DMAC (10 wt \%) solution under magnetic stirring for $3-5 \mathrm{~h}$ at $333 \mathrm{~K}$. The mixed solution was then cast onto a polytetrafluoroethylene (PTFE) board and dried under vacuum at $333 \mathrm{~K}$ for $12 \mathrm{~h}$, and then again at $363 \mathrm{~K}$ for $8 \mathrm{~h}$, to obtain final SPEEK/AIL/ $\mathrm{SiO}_{2}$ ternary composite membranes. The entire preparation process used to prepare the ternary composite membranes is shown in Figure 1. Please note the following abbreviations used in this article: the " $\mathrm{X}$ " within the symbol SPEEK-X/AIL/ $\mathrm{SiO}_{2}-\mathrm{Y}$ denotes the DS of the SPEEK; AIL is the ammonium ionic liquid $\left(\left[\left(\mathrm{CH}_{3} \mathrm{CH}_{2}\right)_{3} \mathrm{NH}^{+}\right]\left[\mathrm{HSO}_{4}{ }^{-}\right]\right.$, TEAS); "Y" is the mass fraction of nano- $\mathrm{SiO}_{2}$ for the total mass of the ternary composite membranes. In the prepared composite membranes, the AIL mass accounted for $35 \%$ of SPEEK used in all prepared composite membranes, since the PEMFC performance using the SPEEK75-35S membrane provided the best result in our previous work [22].

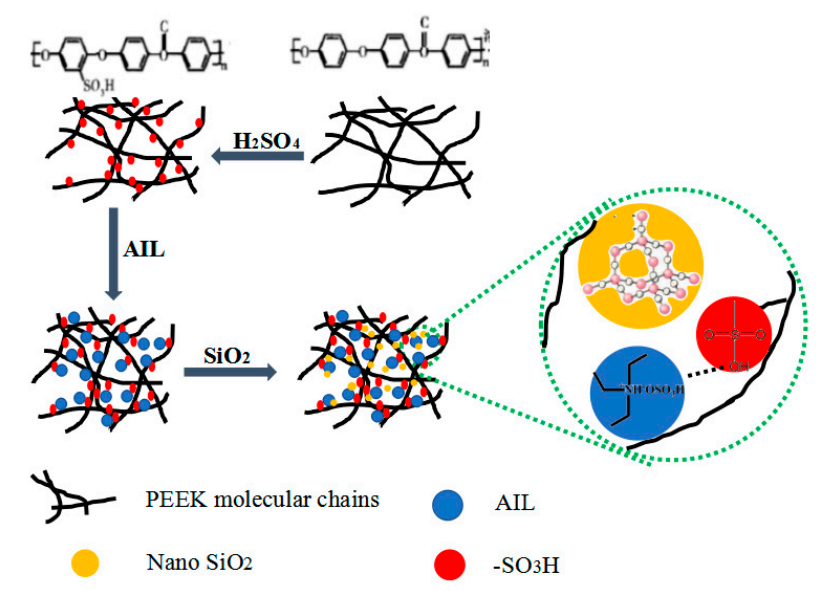

Figure 1. Schematic representation of the ternary composite membrane preparation process.

\subsection{Characterization of Sulfonated Poly(ether ether ketone)/Ammonium Ionic Liquid/Silicon Dioxide Composite Membrane}

\subsubsection{Fourier Transform Infrared Spectra}

FTIR spectra of PEEK, SPEEK, AIL, and SPEEK/AIL/SiO ${ }_{2}$ composite membranes were measured in a wave number range between $600 \mathrm{~cm}^{-1}$ and $4000 \mathrm{~cm}^{-1}$ using a Thermo Scientific Nicolet iS 10 (Thermo Fisher Scientific, Waltham, MA, USA). The spectra were measured in transmittance mode with a resolution of $2 \mathrm{~cm}^{-1}$. 


\subsubsection{X-ray Diffraction}

XRD patterns of SPEEK, SPEEK/AIL, and SPEEK/AIL/ $\mathrm{SiO}_{2}$ ternary composite membranes were recorded using a D-MAX 2500 (Rigaku, Tokyo, Japan). The voltage and current of X-ray tubes were $40 \mathrm{KV}$ and $150 \mathrm{~mA}$, respectively, and XRD patterns were obtained at $2 \theta$, varying between $5^{\circ}$ and $80^{\circ}$.

\subsubsection{Scanning Electron Microscopy}

The morphology of composite membranes was observed using a Jeol scanning electron microscope (SEM, JSM-7800F, JEOS Ltd, Tokyo, Japan).

\subsubsection{Thermal Properties}

To determine the thermal stability of the synthesized SPEEK/AIL/ $\mathrm{SiO}_{2}$ ternary composite membranes, a thermogravimetric analysis (TGA) was conducted under a nitrogen gas atmosphere using a TG 209F1 TGA analyzer (TA instrument, Bochum, Germany) within a temperature range of $303 \mathrm{~K}$ to $873 \mathrm{~K}$ and at a heating rate of $10{ }^{\circ} \mathrm{C} / \mathrm{min}$.

\subsubsection{Ion Exchange Capacity}

The ion exchange capacity (IEC) of SPEEK/AIL/ $\mathrm{SiO}_{2}$ membranes was measured using traditional acid-base titration methods. First, the mass of the ternary composite membrane sample was weighed using an analytical balance, and the sample was then immersed in $20 \mathrm{ml} 2 \mathrm{~mol} / \mathrm{L} \mathrm{NaCl}$ solution for $24 \mathrm{~h}$. The membrane sample was then extracted from the solution and washed, using de-ionized water to remove the residual $\mathrm{NaCl}$. Phenolphthalein was added to the solution as an indicator, and the solution was titrated by $\mathrm{NaOH}$ solution $\left(\mathrm{M}_{\mathrm{NaOH}}=0.01 \mathrm{~mol} / \mathrm{L}\right)$ until a faint pink color was obtained. The volume of the $\mathrm{NaOH}$ solution $\left(V_{\mathrm{NaOH}}\right)$ was recorded. At least three measurements were taken for each membrane sample. The IEC value of the SPEEK/AIL/SiO 2 composite membrane was obtained using Equation (1):

$$
I E C=\frac{V_{\mathrm{NaOH}} \times \mathrm{M}_{\mathrm{NaOH}}}{\text { weight of dry membrane }}
$$

\subsubsection{Proton Conductivity}

The proton conductivity of the SPEEK/AIL and SPEEK/AIL/SiO ${ }_{2}$ membranes was measured using AC impedance spectroscopy in a frequency range of $100 \mathrm{~Hz}$ to $1 \mathrm{MHz}$ and at a voltage amplitude of $10 \mathrm{mV}$, using an electrochemical workstation (CHI660E, Shanghai Chenhua instrument Co. Ltd., Shanghai, China). Each membrane sample was nipped between two carbon-paper electrodes, each with an area of $0.332 \mathrm{~cm}^{2}$. The thickness of the SPEEK/AIL/SiO 2 composite membrane was $50 \mu \mathrm{m}$, and its proton conductivity value was calculated by applying Equation (2):

$$
\sigma=\frac{L}{R \cdot A}
$$

where, $\sigma$ refers to proton conductivity, $R$ is membrane resistance, $L$ is membrane thickness, and $A$ is the contact area of the electrode. The membrane resistance $(R)$ value of SPEEK/AIL $/ \mathrm{SiO}_{2}$ composite membranes was acquired using a Nyquist curve by equivalent circuit, fitting with Z-view software.

2.2.7. Ammonium Ionic Liquid Leaching of Sulfonated Poly(ether ether ketone)/Ammonium Ionic Liquid/ Silicon Dioxide membranes

SPEEK/AIL/ $/ \mathrm{SiO}_{2}$ composite membranes were dried in a vacuum oven at $353 \mathrm{~K}$ until a constant mass was attained $\left(\mathrm{W}_{1} \mathrm{~g}\right)$, and then dipped in de-ionized water at $373 \mathrm{~K}$ for $0.5 \mathrm{~h}$. The membrane samples were then dried again in a vacuum oven at $353 \mathrm{~K}$ until a constant mass $\left(\mathrm{W}_{2} \mathrm{~g}\right)$ was attained, and then re-dipped in de-ionized water for $1 \mathrm{~h}$, dried, and re-weighed $\left(\mathrm{W}_{3} \mathrm{~g}\right)$. The weight of the dry 
samples was measured in the same way after immersion in water for $2 \mathrm{~h}$ and $4 \mathrm{~h}$. AIL leaching of the SPEEK/AIL $/ \mathrm{SiO}_{2}$ composite membranes was then calculated using Equation (3):

$$
\text { AIL leaching }(\%)=\frac{W_{n}-W_{n+1}}{W_{n}}
$$

\section{Results and Discussion}

\subsection{Fourier Transform Infrared Spectra of the Membrane}

The chemical structures of PEEK, SPEEK-75, AIL, and SPEEK-75/AIL/SiO 2 composite membranes were qualitatively analyzed using FTIR spectra, as shown in Figure 2. The absorption peak of pristine PEEK was confirmed at $1492 \mathrm{~cm}^{-1}$, and this demonstrates the existence of a C-C aromatic ring [26], although the peak identity was reduced. The absorption of SPEEK was divided into two peaks, at $1490 \mathrm{~cm}^{-1}$ and $1472 \mathrm{~cm}^{-1}$ [27,28]. Compared to pristine PEEK, the new absorption peaks of SPEEK were at $1024 \mathrm{~cm}^{-1}, 1077 \mathrm{~cm}^{-1}$, and $1254 \mathrm{~cm}^{-1}$, which reflect the existence of sulfonic acid groups within the SPEEK matrix. The three characteristic absorption peaks of the sulfonyl groups can be attributed to asymmetric $\mathrm{O}=\mathrm{S}=\mathrm{O}$ stretching, symmetric $\mathrm{O}=\mathrm{S}=\mathrm{O}$ stretching, and $\mathrm{S}=\mathrm{O}$ stretching, respectively $[28,29]$. The characteristic peak of AIL at $3436 \mathrm{~cm}^{-1}$ shows $-\mathrm{NH}$ stretching vibration. Nitrogen atoms have strong electronegativity, and hydrogen bonds are formed at $3436 \mathrm{~cm}^{-1}$. The peak at $2978 \mathrm{~cm}^{-1}$ represents the stretching vibration absorption of $-\mathrm{CH}_{3}$, and $1396 \mathrm{~cm}^{-1}$ represents the bending absorption of $-\mathrm{CH}_{2}$ when connecting with the positively charged nitrogen center [25]. Characteristic peaks of SPEEK and AIL were also observed in the FTIR spectra of the SPEEK-75/AIL/ $\mathrm{SiO}_{2}$ composite membrane samples, which demonstrates the presence of SPEEK and AIL within the ternary composite membrane. Furthermore, the absorption peaks at $950 \mathrm{~cm}^{-1}$ and $706 \mathrm{~cm}^{-1}$ accorded with the characteristic absorption peaks of silica, which are ascribed to the linear and bending stretching of $\mathrm{Si}-\mathrm{O}-\mathrm{Si}$, respectively [30]. An asymmetric stretching vibration peak of $\mathrm{Si}-\mathrm{O}-\mathrm{Si}$ at $1075 \mathrm{~cm}^{-1}$ was anticipated; however, this peak was found to overlap with the peak associated with the symmetric stretching of the $\mathrm{O}=\mathrm{S}=\mathrm{O}$ of sulfonyl group at $1077 \mathrm{~cm}^{-1}$, although the absorption peak was much smaller than that of the SPEEK sample. These FTIR spectra results indicate that the SPEEK matrix had been incorporated with $\mathrm{AIL}$ and $\mathrm{SiO}_{2}$. In other words, the results indicate completion of SPEEK/AIL/ $\mathrm{SiO}_{2}$ ternary composite membrane preparation.

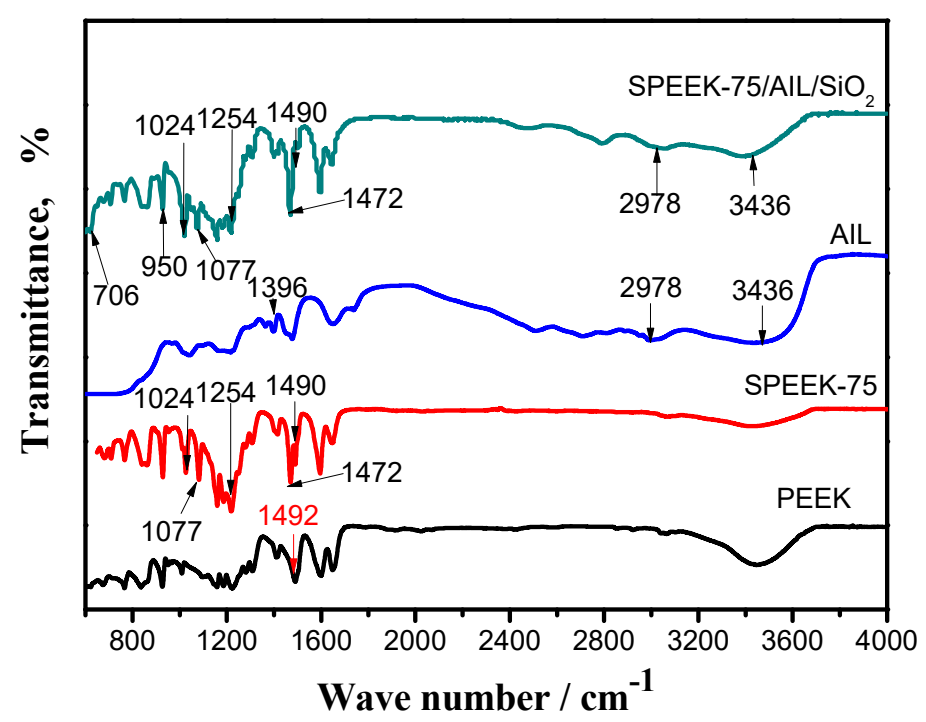

Figure 2. The Fourier transform infrared (FTIR) spectra of the poly(ether ether ketone) (PEEK), sulfonated poly(ether ether ketone) (SPEEK)-75, AIL, and SPEEK-75/AIL/SiO 2 composite membranes. 


\subsection{Microstructure of Membranes}

SPEEK consists of a hydrophobic aromatic backbone and a hydrophilic side chain (terminated with sulfonic acid groups), and it has distinct nanophase separation. The aromatic backbone is formed in a hydrophobic phase and provides mechanical strength, whereas the side chain is aggregated into ionic clusters [31]. The morphologies of the prepared membranes were explored by SEM and XRD. Figure 3 shows SEM images of SPEEK-75/AIL and SPEEK-75/AIL/SiO 2 membranes with different nano-SiO $\mathrm{S}_{2}$ contents. It is clear from the SEM images in Figure 3a that SPEEK-75/AIL membranes have a smooth uniform morphology, with no obvious defects. The ternary composite membrane shown in Figure $3 b-f$ shows that nano- $\mathrm{SiO}_{2}$ particles are entrapped within the continuous matrix, which suggests that the SPEEK network surrounding the nano- $\mathrm{SiO}_{2}$ particles forms a strong backbone, leading to flexibility of the ternary composite membrane.
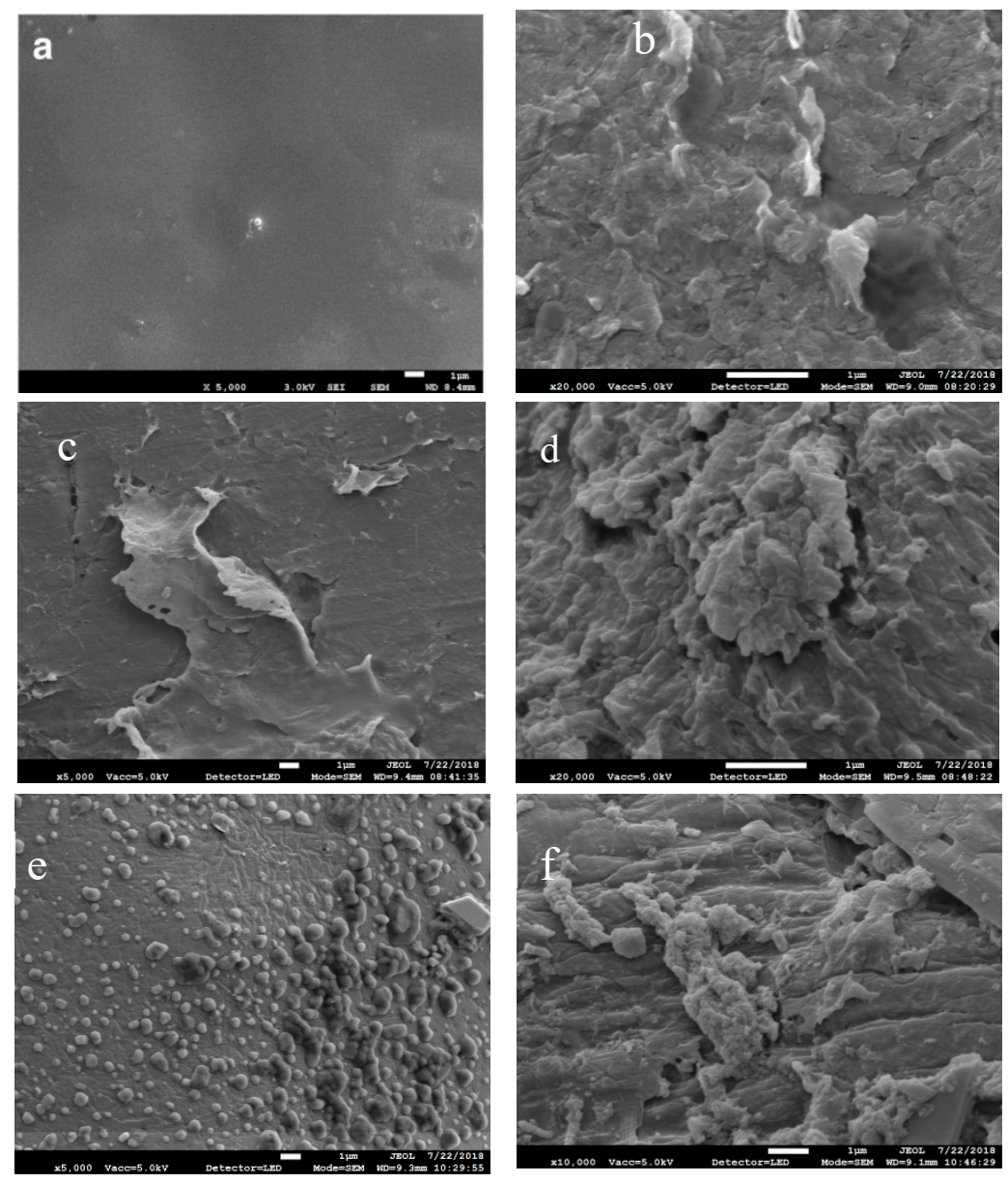

Figure 3. Scanning electron microscopy (SEM) images of membranes: (a) SPEEK-75/AIL; (b) SPEEK-75/ $\mathrm{AIL} / \mathrm{SiO}_{2}-5$; (c) SPEEK-75/AIL/SiO $2-8$; (d) SPEEK-75/AIL/SiO $2-10$; (e) SPEEK-75/AIL/SiO $2-13$; (f) SPEEK-75/AIL/ $\mathrm{SiO}_{2}-17$.

XRD was used to further investigate the influence of AIL and $\mathrm{SiO}_{2}$ on the morphology of the SPEEK matrix, and Figure 4 shows the XRD patterns of SPEEK-75, SPEEK-75/AIL, and SPEEK-75/AIL/ $\mathrm{SiO}_{2}$ membranes with different nano-SiO${ }_{2}$ contents. The XRD profiles show that all membranes have a broad crystalline band at $2 \theta$ equaling $12^{\circ}-30^{\circ}$, which corresponds to the ordered stacking of the hydrophobic backbone [32]. Compared to the SPEEK membrane, the intensity decline of this band in the SPEEK-75/AIL membrane can be attributed to the plasticizing effect of AIL on the hydrophobic domains of SPEEK. The plasticizing effect weakens the interaction between backbones and thus destroys the ordered stacking, thereby rendering the SPEEK-75/AIL membrane 
more flexible [33]. The crystallinity of the ternary composite membrane decreased with an increase in the nano- $\mathrm{SiO}_{2}$ content, from $5 \%$ to $17 \%$. These results indicate that the amorphous domain is greatly fortified in the ternary composite membrane.

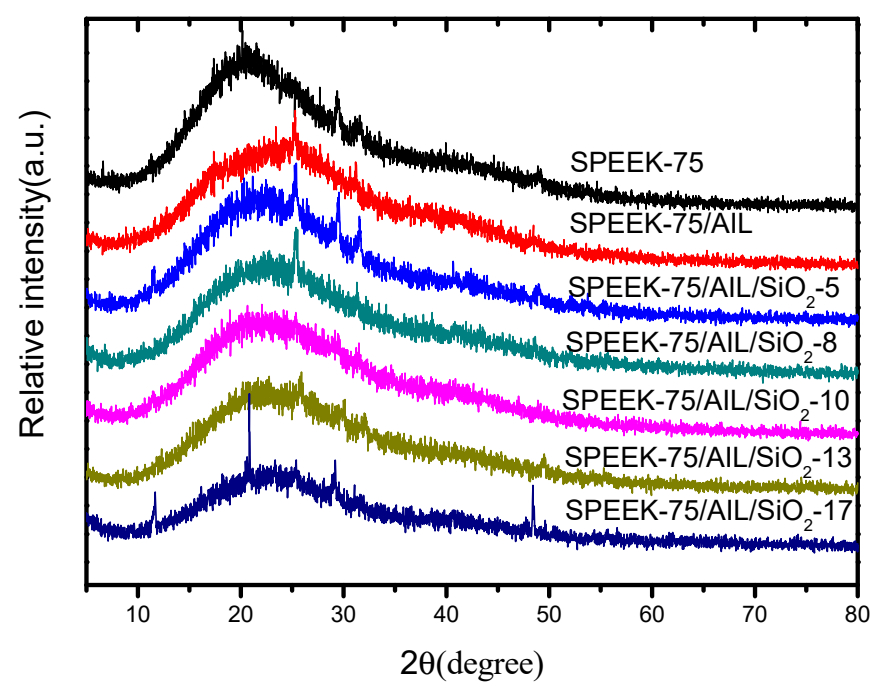

Figure 4. X-ray diffraction (XRD) patterns of the SPEEK/AIL/SiO 2 composite membranes.

\subsection{Thermogravimetric Analysis}

TGA was used to study the thermal stability of the SPEEK/AIL/SiO 2 composite membranes, with respect to their potential use in HT-PEMFC applications. Figure 5 shows the mass loss of SPEEK/AIL/ $\mathrm{SiO}_{2}$ composite membranes in a temperature range from $303 \mathrm{~K}$ to $873 \mathrm{~K}$, and three mass loss stages are evident within this range. The first stage (350-373 K) represents the evaporation of absorbed water and residual solvent within the composite membranes [17]; the second stage (523-723 K) represents decomposition of the sulfonic acid group of SPEEK [29], AIL, and hydroxyl components adsorbed on the $\mathrm{SiO}_{2}$ sol; and the third stage (>723 K) represents decomposition of the SPEEK polymer chain. The thermal stability of the SPEEK-75/AIL $/ \mathrm{SiO}_{2}-8$ composite membrane is superior to that of the other two membranes, and thus this membrane is suitable for use with HT- PEMFC.

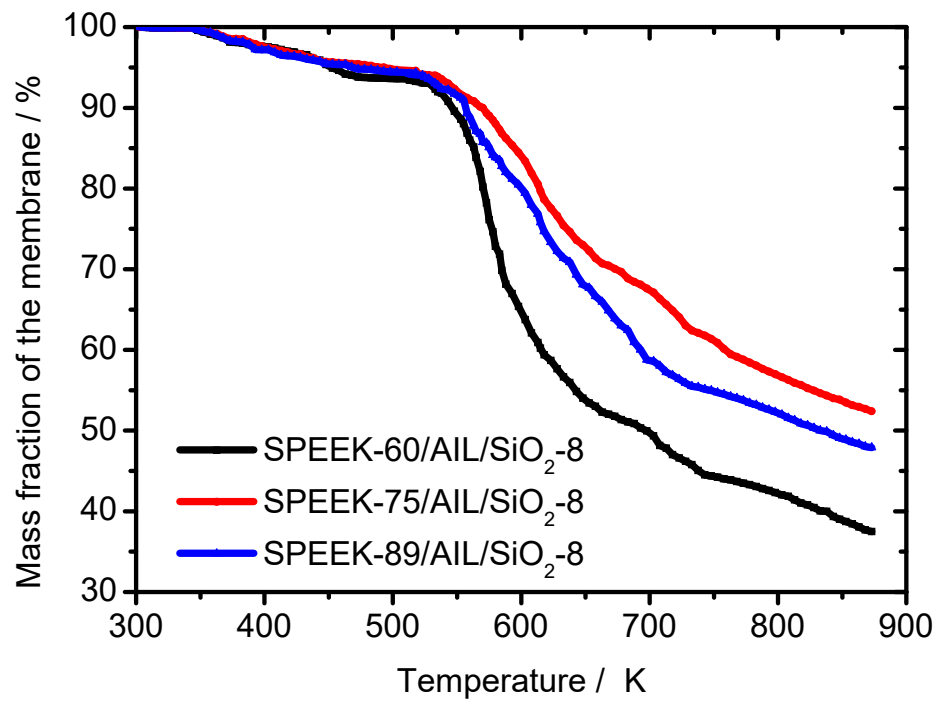

Figure 5. Thermogravimetric analysis (TGA) of the SPEEK/AIL/ $/ \mathrm{SiO}_{2}$ composite membranes. 


\subsection{Ion Exchange Capacity}

The IEC is usually defined as the number of sulfonic acid group per gram of the sulfonated polymer membrane, and it can be used to indicate sulfonic acid groups present within the polymer matrix that facilitate proton transfer. It also offers a credible approximation of membrane proton conductivity. The IEC value of SPEEK/AIL/SiO 2 composite membranes with different $\mathrm{DS}$ and $\mathrm{SiO}_{2}$ contents are provided in Figure 6, where it is evident that the IEC values of the SPEEK/AIL $/ \mathrm{SiO} 2$ composite membranes have a tendency to increase with an increase in the $\mathrm{SiO}_{2}$ content, and tend to increase and then decrease with an increase in DS. For example, the IEC value increased from 1.2 to $3.25 \mathrm{meq} / \mathrm{g}$ with an increase in the $\mathrm{SiO}_{2}$ content within the membrane, from $0 \%$ to $17 \%$, while the IEC value first increased from 0.5 to $1.86 \mathrm{meq} / \mathrm{g}$ with an increase in the DS of the membrane from 50 to 75 , but then decreased from 1.86 to $1.11 \mathrm{meq} / \mathrm{g}$ with an increase in DS from 75 to 96 . These tendencies were further confirmed by the results of proton conductivity for the SPEEK/AIL $/ \mathrm{SiO}_{2}$ membranes, as shown in the following section. Compared to the SPEEK/AIL membrane, the ternary composite membranes show enhanced IEC values. Generally speaking, the higher IEC values are attributed to the larger number of acid groups present in the SPEEK/AIL/SiO 2 ternary composite membrane. This enhanced acidic property is also expected to improve membrane proton conductivity [34].
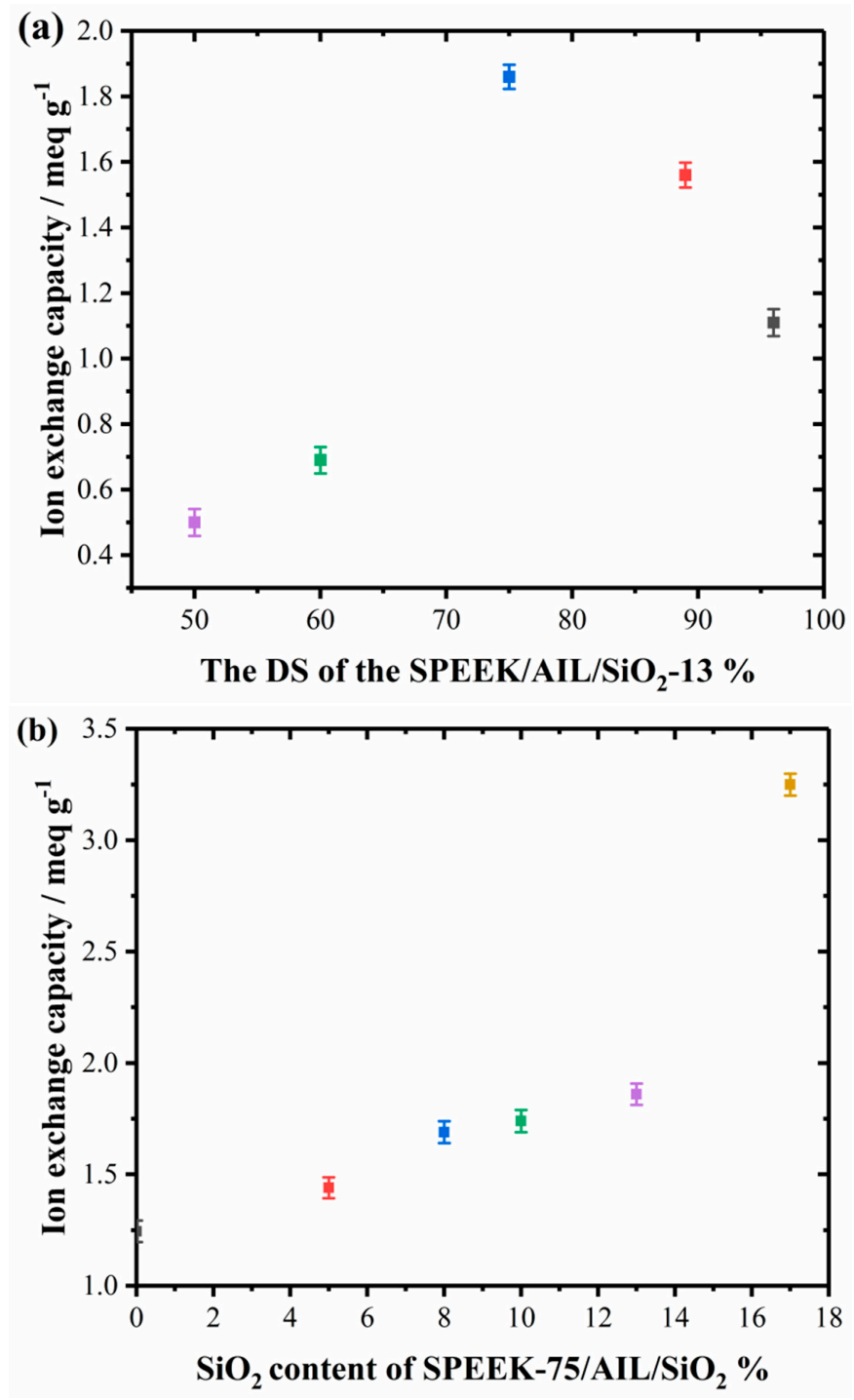

Figure 6. Ion exchange capacity (IEC) of the SPEEK/AIL/SiO 2 composite membranes with different degree of sulfonation (DS) (a) and $\mathrm{SiO}_{2}$ content (b). 


\subsection{Proton Conductivity}

The proton conductivities of the SPEEK/AIL/ $\mathrm{SiO}_{2}$ composite membrane with different DSs at $373 \mathrm{~K}$ and different $\mathrm{SiO}_{2}$ contents at different temperatures are shown in Figure 7a,b. A maximum proton conductivity of $8.889 \mathrm{mS} \mathrm{cm}^{-1}$ is evident in Figure $7 \mathrm{a}$, which occurs with a DS of 75 at $373 \mathrm{~K}$ in the ternary composite membrane. With an increase in the DS, the proton conductivity of the composite membrane followed the same tendency as the IEC values. The ammonium ionic liquid in the SPEEK/AIL/ $\mathrm{SiO}_{2}$ composite membrane not only provides abundant water-free jumping points, but also forms an acid-base pair $\left(\mathrm{SO}_{3} \mathrm{H}-\mathrm{NH}_{2}\right)$ along the channel surface. The acid-base pairs offer new pathways for intensifying proton transfer and thus increase the proton conductivity of the composite membrane. As shown in Figure $7 \mathrm{~b}$, the proton conductivity of the SPEEK-75/AIL/SiO 2 membrane was observed to increase with an increase in the $\mathrm{SiO}_{2}$ content within the composite membrane, which was expected. The nano- $\mathrm{SiO}_{2}$ particles within the composite membrane have a spatial net structure that not only stores water, but also anchors the AIL within the polymer matrix to prevent AIL leaching. Moreover, the surface of $\mathrm{SiO}_{2}$ contains a large number of hydroxyl groups, and also increases the water content in the composite membrane. With an increase in the $\mathrm{SiO}_{2}$ content, the cross-linking degree of the membrane was enhanced. In addition, the ability of the membrane to retain water and AIL increased, and the number of proton carrier sites also increased, leading to enhancement of membrane proton conductivity. The proton conductivity of the SPEEK-75/AIL/SiO ${ }_{2}-17$ composite membrane reached $10.73 \mathrm{mS} \mathrm{cm}^{-1}$ at $393 \mathrm{~K}$. Figure $7 \mathrm{~b}$ also reveals that the proton conductivity of all the prepared membranes with different $\mathrm{SiO}_{2}$ contents monotonically increased with an increase in temperature. For example, the proton conductivity of SPEEK-75/AIL/SiO ${ }_{2}-17$ increased from 4.322 to $10.73 \mathrm{mS} \mathrm{cm}^{-1}$ with a temperature increase from $313 \mathrm{~K}$ to $393 \mathrm{~K}$.

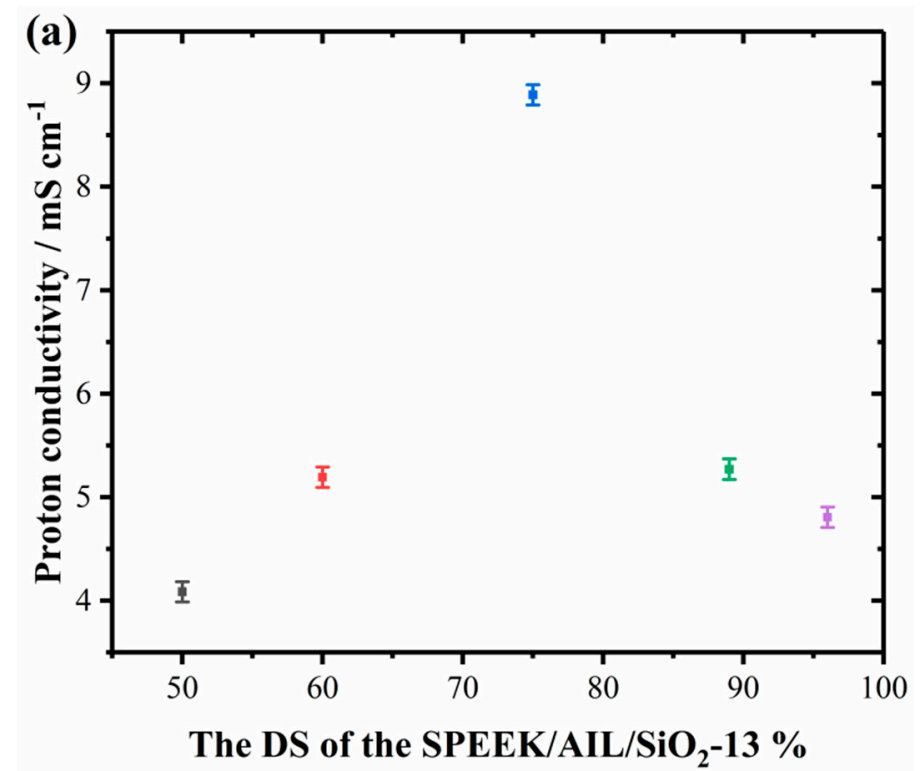

Figure 7. Cont. 


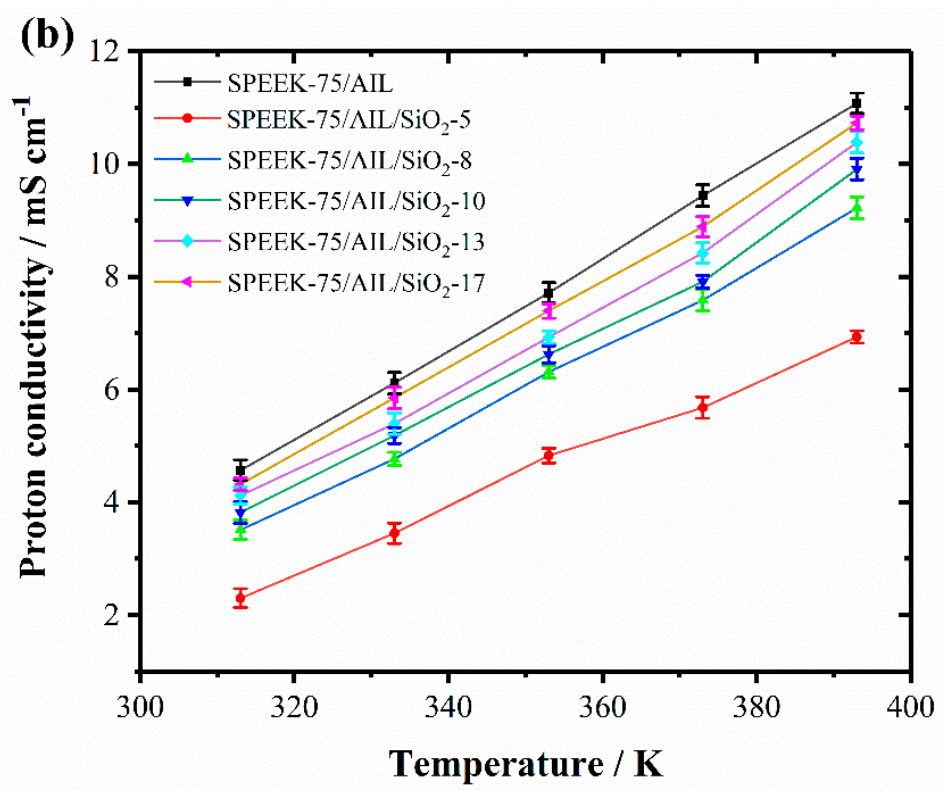

Figure 7. The proton conductivity of SPEEK/AIL/ $\mathrm{SiO}_{2}$ membranes with different DSs (a) and $\mathrm{SiO}_{2}$ content (b).

To further study the influence of the $\mathrm{SiO}_{2}$ content on the proton conductivity of the SPEEK/AIL/ $\mathrm{SiO}_{2}$ composite membrane, the activation energy $(E a)$ for proton conduction through the membrane was calculated using Equation (4):

$$
\sigma=\sigma_{0} \exp \left(\frac{-E_{a}}{R T}\right)
$$

where $\sigma_{0}$ is the pre-exponential factor, $R$ is the ideal gas constant $\left(8.314 \mathrm{~J} \mathrm{~mol}^{-1} \mathrm{~K}^{-1}\right), T$ is the thermodynamic temperature, and $E_{\mathrm{a}}$ is activation energy for proton transfer. The value of $E_{\mathrm{a}}$ was estimated from the slope of a linear fitted curve of $\log \sigma$ versus $1000 / \mathrm{T}$, and the results are shown in Table 1. The results were approximately equal to those reported in literature [35], and the SPEEK membrane reached a Grotthuss-type $E_{\mathrm{a}}$ of $14.0 \mathrm{~kJ} \mathrm{~mol}^{-1}$. In contrast, the incorporation of nano- $\mathrm{SiO}_{2}$ caused the $E_{\mathrm{a}}$ value of the SPEEK/AIL composite membrane to reduce to 12.3, 11.9, 11.7, 11.5 , and $11.3 \mathrm{~kJ} \mathrm{~mol}^{-1}$ with an $\mathrm{SiO}_{2}$ doping content of $5 \%, 8 \%, 10 \%, 13 \%$, and $17 \%$, respectively. In conclusion, the reduced $E_{\mathrm{a}}$ and improved proton conductivity further evidence the conductive ability of the ammonium-type ionic liquids within the polymer electrolyte membrane. The conductive ability is improved by the existence of channels allowing Grotthuss-type proton transport, which is achieved through the incorporation of nano-SiO${ }_{2}$ into the SPEEK/AIL membrane matrix.

Table 1. The activation energy for proton conduction through SPEEK/AIL/SiO 2 composite membranes.

\begin{tabular}{|c|c|}
\hline Membrane & Activation Energy $\left(\mathrm{kJ} \mathrm{mol}^{-1}\right)$ \\
\hline SPEEK-75/AIL & 14.0 \\
\hline SPEEK-75/AIL/ $/ \mathrm{SiO}_{2}-5$ & 12.3 \\
\hline SPEEK-75/AIL/ $\mathrm{SiO}_{2}-8$ & 11.9 \\
\hline SPEEK-75/AIL/SiO $2-10$ & 11.7 \\
\hline SPEEK-75/AIL/SiO $2-13$ & 11.5 \\
\hline SPEEK-75/AIL/SiO $2-17$ & 11.3 \\
\hline
\end{tabular}

\subsection{Ammonium Ionic Liquid Leaching}

Generally speaking, IL leaching of the membrane is a problem for the IL-doped electrolyte membrane, as it reduces proton conductivity and thus decreases the performance of the fuel cell. 
During HT-PEMFC operation, water molecules are yielded at the cathode in the form of steam, and it is believed that some of these caused AIL leaching from the composite membrane. To investigate the retention of AIL within the SPEEK/AIL/ $\mathrm{SiO}_{2}$ membrane, AIL loss was measured under extreme conditions (immersing the membrane sample into de-ionized water). Figure 8a,b show AIL leaching of SPEEK/AIL/ $/ \mathrm{SiO}_{2}$ composite membrane samples with different $\mathrm{DS}$ and $\mathrm{SiO}_{2}$ contents as a function of time when dipped in de-ionized water. It is evident that all membrane samples show quick AIL loss in the initial hour from free-form AIL leaching [33]. Free-form AIL has a loose connection with the membrane substrate, and is mostly situated at the surface of the SPEEK/AIL/SiO ${ }_{2}$ composite membrane following physical adsorption. After a period of $1 \mathrm{~h}$, the AIL content within the ternary composite membranes remained unchanged with an increase in the measuring time, which showed that residual AIL was in a bound form. AIL in bound form has strong connections with $-\mathrm{SO}_{3} \mathrm{H}$ and $\mathrm{SiO}_{2}$ groups within the composite membrane. AIL leaching of the SPEEK/AIL/SiO 2 composite membrane was between $20 \%$ and $30 \%$, which was lower than that of the SPEEK/AIL membrane. The nano-SiO net structure and SPEEK twist strengthened the tightness of the net structure, which effectively reduced AIL leaching from the SPEEK/AIL/ $\mathrm{SiO}_{2}$ composite membrane.
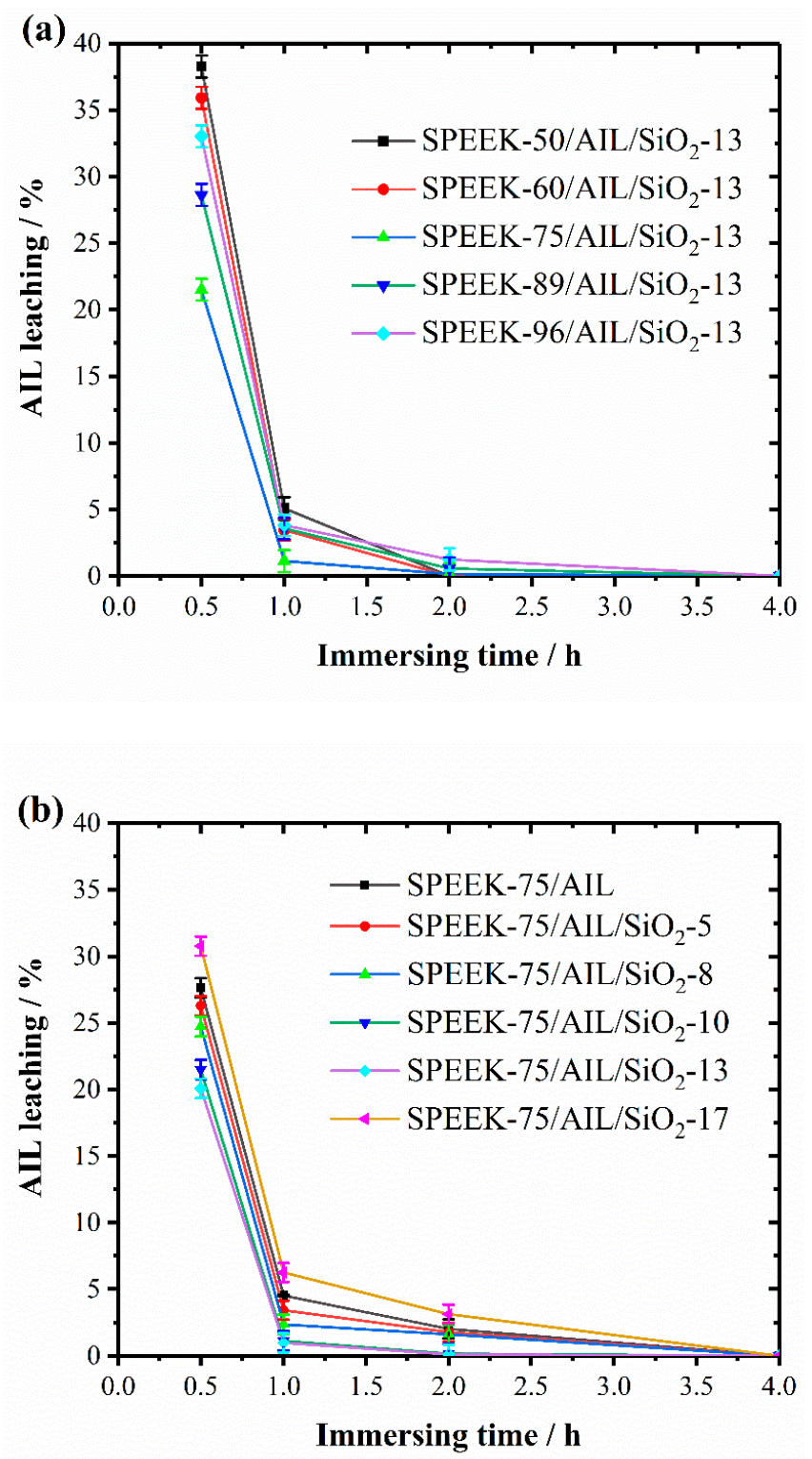

Figure 8. The AIL leaching of the SPEEK/AIL/SiO 2 composite membranes with different DSs (a) and $\mathrm{SiO}_{2}$ content (b) as a function of time. 


\section{Conclusions}

SPEEK/AIL $/ \mathrm{SiO}_{2}$ ternary composite membranes were fabricated using a solution casting method. FTIR spectra results indicated that the SPEEK matrix had been incorporated with AIL and $\mathrm{SiO}_{2}$. SEM and XRD images showed that the incorporation of nano-SiO${ }_{2}$ rendered the ternary composite membrane more flexible. Furthermore, TGA curves of the prepared ternary composite membranes indicated that the membranes were appropriate for use in HT-PEMFC. The IEC value of the SPEEK/AIL/ $\mathrm{SiO}_{2}$ composite membranes showed a tendency to increase with an increase in the $\mathrm{SiO}_{2}$ content, but a tendency to increase and then decrease with an increase in the DS. Higher IEC values were attributed to the presence of a greater number of acid groups within the ternary polymer electrolyte membrane. With an increase in the $\mathrm{SiO}_{2}$ within the ternary composite membrane, there was an enhancement of the cross-linking degree of the membrane, which improved the membrane's AIL retention ability and proton conductivity. AIL leaching from SPEEK/AIL $/ \mathrm{SiO}_{2}$ membranes was between $20 \%$ and $30 \%$, which was lower than that of SPEEK/AIL membranes. In this paper, incorporation of nano-SiO $\mathrm{S}_{2}$ into the SPEEK/AIL matrix raised proton conductivity and the AIL retention of the membranes, and the membranes therefore have potential application for use in HT-PEMFC.

Author Contributions: S.Q. and X.L. designed experiments; M.L., C.Z. and Y.S. carried out experiments and analyzed experimental results. S.Q. and M.L. wrote the manuscript. J.L. supervised the work and revised the manuscript. J.D. and W.W. provided constructive suggestions about this work.

Funding: This research was funded by the National Natural Science Foundation of China (No. 21306095).

Acknowledgments: The authors are grateful for the financial support from the National Natural Science Foundation of China.

Conflicts of Interest: The authors declare no conflict of interest.

\section{References}

1. Yi, B.L. Fuel Cell- Principle Technology Application; Chemical Industry Press: Beijing, China, 2003.

2. Chandan, A.; Hattenberger, M.; El-kharouf, A. High temperature polymer electrolyte membrane fuel cells (PEMFC)-A review. J. Power Sources 2013, 231, 264-278. [CrossRef]

3. Barbati, A.C.; Kirby, B.J. Electrokinetic measurements of thin Nafion films. Langmuir 2014, 30, $1985-1993$. [CrossRef] [PubMed]

4. Smitha, B.; Sridhar, S.; Khan, A.A. Solid polymer electrolyte membranes for fuel cell applications-A review. J. Membr. Sci. 2015, 259, 10-26. [CrossRef]

5. Muriithi, B.; Loy, D.A. Proton conductivity of Nafion/ex situ Stöber silica nanocomposite membranes as a function of silica particle size and temperature. J. Mater. Sci. 2014, 49, 1566-1573. [CrossRef]

6. Jalili, J.; Borsacchi, S.; Tricoli, V. Proton conducting membranes in fully anhydrous conditions at elevated temperature: Effect of Nitrilotris (methylenephosphonic acid) incorporation into Nafion- and poly (styrenesulfonic acid). J. Membr. Sci. 2014, 469, 162-173. [CrossRef]

7. Hooshyari, K.; Javanbakht, M.; Shabanikia, A.; Enhessari, M. Fabrication $\mathrm{BaZrO}_{3} / \mathrm{PBI}$-based nanocomposite as a new proton conducting membrane for high temperature proton exchange membrane fuel cells. J. Power Sources 2015, 276, 62-72. [CrossRef]

8. Li, Q.F.; He, R.H.; Jensen, J.O.; Bjerrum, N.J. Approaches and recent development of polymer electrolyte membranes for fuel cells operating above $100{ }^{\circ} \mathrm{C}$. Chem. Mater. 2003, 15, 4896-4915. [CrossRef]

9. Sekhon, S.S.; Kaur, D.P.; Park, J.S.; Yamada, K. Ion transport properties of ionic liquid based gel electrolytes. Electrochim. Acta 2012, 60, 366-374. [CrossRef]

10. Yan, S.J.; Zeng, S.J.; Su, X.L.; Yin, H.J.; Xiong, Y.Q.; Xu, W.J. $\mathrm{H}_{3} \mathrm{PO}_{4}$-doped 1,2,4-triazole-polysiloxane proton conducting membrane prepared by sol-gel method. Solid State Ion. 2011, 198, 1-5. [CrossRef]

11. Che, Q.T.; He, R.H.; Yang, J.S.; Feng, L.; Savinell, R.F. Phosphoric acid doped high temperature proton exchange membranes based on sulfonated polyetheretherketone incorporated with ionic liquids. Electrochem. Commun. 2010, 12, 647-649. [CrossRef] 
12. Che, Q.T.; Zhou, L.; Wang, J.L. Fabrication and characterization of phosphoric acid doped imidazolium ionic liquid polymer composite membranes. J. Mol. Liq. 2015, 206, 10-18. [CrossRef]

13. Wang, R.J.; Wu, X.M.; Yan, X.M.; He, G.H.; Hu, Z.W. Proton conductivity enhancement of SPEEK membrane through n-BuOH assisted self-organization. J. Membr. Sci. 2015, 479, 46-54. [CrossRef]

14. Rangasamy, V.S.; Thayumanasundaram, S.; Greef, N.D.; Seo, J.W.; Locquet, J.P. Preparation and

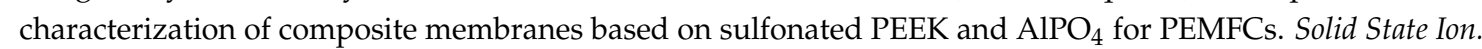
2012, 216, 83-89. [CrossRef]

15. Mossayebi, Z.; Saririchi, T.; Rowshanzamir, S.; Parnian, M.J. Investigation and optimization of physicochemical properties of sulfated zirconia/sulfonated poly (ether ether ketone) nanocomposite membranes for medium temperature proton exchange membrane fuel cells. Int. J. Hydrogen Energy 2016, 41, 12293-12306. [CrossRef]

16. Li, L.; Shang, Y.M.; Feng, S.G.; Wang, Y.Z.; Jiang, J.Z.; Xie, X.F. Crosslinked SPEEK/SiO 2 hybrid proton exchange membranes for direct methanol fuel cells. J. Tsinghua Univ. (Nat. Sci. Ed.) 2010, 50, 900-904.

17. Salarizadeh, P.; Javanbakht, M.; Pourmahdian, S.; Beydaghi, H. Influence of amine-functionalized iron titanate as filler for improving conductivity and electrochemical properties of SPEEK nanocomposite membranes. Chem. Eng. J. 2016, 299, 320-331. [CrossRef]

18. Lee, C.; Jo, S.M.; Choi, J.; Baek, K.Y.; Truong, Y.B.; Kyratzis, I.L.; Shul, Y.G. $\mathrm{SiO}_{2}$ / sulfonated poly ether ether ketone (SPEEK) composite nanofiber mat supported proton exchange membranes for fuel cells. J. Mater. Sci. 2013, 48, 3665-3671. [CrossRef]

19. Miranda, D.F.; Versek, C.; Tuominen, M.T.; Rusell, T.P.; Watkins, J.J. Cross-linked block copolymer/ionic liquid self-assembled blends for polymer gel electrolytes with high ionic conductivity and mechanical strength. Macromolecules 2013, 46, 9313-9323. [CrossRef]

20. Che, Q.; Sun, B.; He, R. Preparation and characterization of new anhydrous conducting membranes based on composites of ionic liquid trifluoroacetic propylamine and polymers of sulfonated poly (ether ether) ketone or polyvinylidenefluoride. Electrochim. Acta 2008, 53, 4428-4434. [CrossRef]

21. Jothi, P.R.; Dharmalingam, S. An efficient proton conducting electrolyte membrane for high temperature fuel cell in aqueous-free medium. J. Membr. Sci. 2014, 450, 389-396. [CrossRef]

22. Qu, S.G.; Sun, Y.Y.; Li, J.L. Sulfonate Poly(ether ether ketone) Incorporated with Ammonium Ionic Liquids for Proton Exchange Membrane Fuel Cell. Ionics 2017, 23, 1607-1611. [CrossRef]

23. Zhang, H.; Zhang, T.; Wang, J.; Pei, F.; He, Y.; Liu, J. Enhanced proton conductivity of sulfonated poly(ether ether ketone) membrane embedded by dopamine-modified nanotubes for proton exchange membrane fuel cell. Fuel Cells 2013, 13, 1155-1165. [CrossRef]

24. Dong, Y.F.; Tan, X.L.; Guo, Q.; Li, X.; Li, D.; Li, M. Testing the sulfonation degree of SPEEK and its effect on the properties of proton exchange membrane. Phys. Test. Chem. Anal. Part A 2011, 47, 535-538.

25. Attri, P.; Venkatesu, P. Ammonium ionic liquids as convenient co-solvents for the structure and stability of succinylated Con A. J. Chem. Thermodyn. 2012, 52, 78-88. [CrossRef]

26. Jaafar, J.; Ismail, A.F.; Mustafa, A. Physicochemical study of poly(ether ether ketone) electrolyte membranes sulfonated with mixtures of fuming sulfuric acid and sulfuric acid for direct methanol fuel cell application. Mater. Sci. Eng. A 2007, 460, 475-484. [CrossRef]

27. Devaux, J.; Delimoy, D.; Daoust, D.; Legras, R.; Mercier, J.P.; Strazielle, C.; Nield, E. On the molecular weight determination of a poly(aryl-ether-ether-ketone) (PEEK). Polymer 1985, 26, 1994-2000. [CrossRef]

28. Ismail, A.F.; Othman, N.H.; Mustafa, A. Sulfonated polyether ether ketone composite membrane using tungstosilicic acid supported on silica-aluminium oxide for direct methanol fuel cell (DMFC). J. Membr. Sci. 2009, 329, 18-29. [CrossRef]

29. Xu, T.; Hou, W.; Wu, X.S.H.; Li, X.; Wang, J.; Jiang, Z. Sulfonated titania submicrospheres-doped sulfonated poly(ether ether ketone) hybrid membranes with enhanced proton conductivity and reduced methanol permeability. J. Power Sources 2011, 196, 4934-4942. [CrossRef]

30. Silverstein, R.M.; Webster, F.X.; Kiemle, D.J. Spectrometric Identification of Organic Compounds, 7th ed.; John Wiley: New York, NY, USA, 2005; p. 107.

31. Schmidt-Rohr, K.; Chen, Q. Parallel cylindrical water nanochannels in Nafion fuel-cell membranes. Nat. Mater. 2008, 7, 75-83. [CrossRef] 
32. Kawaguti, C.A.; Dahmouche, K.; Gomes, A.S. Nanostructure and properties of proton-conducting sulfonated poly(ether ether ketone) (SPEEK) and zirconia- SPEEK hybrid membranes for direct alcohol fuel cells: Effect of the nature of swelling solvent and incorporation of heteropolyacid. Polym. Int. 2012, 61, 82-92. [CrossRef]

33. Zhang, H.Q.; Wu, W.J.; Wang, J.T.; Zhang, T.; Shi, B.B.; Liu, J.D.; Cao, S.K. Enhanced anhydrous proton conductivity of polymer electrolyte membrane enabled by facile ionic liquid-based hoping pathways. J. Membr. Sci. 2015, 476, 136-147. [CrossRef]

34. Ke, C.C.; Li, X.J.; Shen, Q.; Qu, S.G.; Shao, Z.G.; Yi, B.L. Investigation on sulfuric acid sulfonation of in-situ sol-gel derived Nafion $/ \mathrm{SiO}_{2}$ composite membrane. Int. J. Hydrogen Energy 2011, 36, 3606-3613. [CrossRef]

35. Tripathi, B.P.; Shahi, V.K. Surface redox polymerized SPEEK-MO $-\mathrm{PANI}(\mathrm{M}=\mathrm{Si}$, Zr and Ti) composite polyelectrolyte membranes impervious to methanol. Colloids Surf. A 2009, 340, 10-19. [CrossRef]

2018 by the authors. Licensee MDPI, Basel, Switzerland. This article is an open access article distributed under the terms and conditions of the Creative Commons Attribution (CC BY) license (http://creativecommons.org/licenses/by/4.0/). 